\title{
Words ordering and corresponding verb-subject agreements in English-Arabic machine translation: Hybrid-based approach
}

\author{
${ }^{1}$ Mohammed M. Abu Shquier, ${ }^{2 *}$ Omer M. Abu Shqeer \\ ${ }^{1}$ University of Tabuk \\ ${ }^{2}$ Taibah University \\ Email:1'mabushquier@ut.edu.sa, ${ }^{2}$ abushqeer@hotmail.co.uk
}

Abstract. Recently Machine Translation (MT) has become a testing ground for many ideas in artificial intelligence (AI) as well as linguistics. Word ordering plays an important role in the translation process between languages. This research is attempting to examine the implications of using verb subject object (VSO) and subject verb object (SVO) words order on the agreement requirements in MT. Approach: The main objective of this research is to develop an EnglishArabic Hybrid-Based Machine Translation (EA-HBMT) to improve the quality of MT from English to Arabic. Transfer-based MT is used to obtain an intermediate representation that captures the "meaning" of the original sentence in order to generate the correct translation. Example based-technique is used as well to handle the irregular cases. Semantic analysis process is mainly conducted to detect the statements that require the use of SVO construction rather than VSO. Results: we have constructed an agreement and ordering tests suite; that has been used in testing different agreement and ordering features in four Arabic MT systems, they are, ALKAFI, GOOGLE and TARJIM SAKHR versus EA-HBMT. These examples have been used in exploring and evaluating the agreement and ordering problems throughout three experiments. In the first experiment we have classified the problems that cause that agreement and ordering into twelve and we compare between the four systems outputs with the original translation of the input text based on these twelve problems. In the second experiment we tested each statement separately, by comparing the particular on-line translation with the original human translation based on the number of the correct translated words in the target language. Conclusion: Based on the achieved results, we have managed to perform the Symantec analysis within Arabic source texts by using hybrid-based machine translation and also achieved reasonable improvements in translation quality over related approaches.

Keywords: MT, agreement, word-ordering, SVO, VSO, affixes, EA-HBMT.

* Corresponding address :

Omer M. Abu Shqeer,

Taibah University,

Email: abushqeer@hotmail.co.uk 


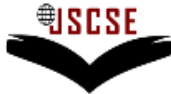

DOI: 10.7321/jscse.v2.n8.5

\section{Introduction}

Ryding (2005) stated that agreement is the feature compatibility between words in a phrase or a clause. He attested to the common usage of Subject-Verb-Object (SVO) order for the headline of a newspaper, while the lead sentence of the article may recapitulate the same sentence in the VerbSubject-Object (VSO) order appropriate to discourse-initial contexts. (Wickens 1980) defined the agreement as "a relationship between verbs, nouns, pronouns....and adjectives". While Corbett (2001) define it as "systematic covariance between a semantic or formal property of one element and a formal property of another.", he used the terms "controller" to refer to the element which determines the agreement, "target" to refer to the element whose form is determined by agreement, and "domain" to refer to the syntactic environment in which agreement occurs [22][9][26]. Attia (2008) stated that Arabic has rich agreement morphology which allows it to show agreement relations between various elements in the sentence.

There are five morpho-syntactic features involved in agreement in Arabic: number (singular, dual and plural), gender (feminine and masculine), person (1st, 2nd, and 3rd), case (nominative, accusative and genitive) and definiteness (definite and indefinite) [8].

Noun-adjective shows strongest agreement where four of the five agreement features are involved: number, gender, case and definiteness, second strongest agreement are the pre-verbal position subject where verbs are required to agree with their subjects in number, gender and person, thus it is clear that there is a correlation between word order and verbal agreement in Standard Arabic (SA), i.e. full agreement in SVO order and partial agreement in VSO order.

Al-Jarf (2007) categorised the need to use VSO word order against the use of VSO word order as follows: SVO structures are used mostly in (nominal sentences and clauses):

(i) sentences consisting of a subject and a predicate.

(ii) sentences beginning with emphatic آن كُ

(iii) sentences beginning with auxiliary

(iv) sentences beginning with the negative particle $\gamma$.

(v) after ظن 'thought' group.

(vi) after قال 'said'.

(vii) after أرى 'showed'

(viii) in answer to certain interrogatives.

On the other hand, VSO structures are used mostly in (verbal sentences):

(i) Conditional sentences beginning with certain particles.

(ii) When independent subject pronouns are deleted. Independent pronoun usage in subject position is discourse-based.

(iii) After sentence initial adverbials and prepositional phrases,

(iv) in passive clauses ([24][5]).

The main goal of this research is the improvement of English-Arabic MT. The motivation of this research is the willing to have an excellent quality of MT from English to Arabic, and to support the researches in this field where most of the available E-A MTs are commercial products (i.e. they are black-boxes for the researchers, and this is one of the constraints and restrictions of our research, but at the same time show the importance of this research). This research is attempting to examine the implications of using verb subject object (VSO) and subject verb object (SVO) words order on the agreement requirements in MT. We suggest a solution of different layers, transfer-based MT is used to obtain an intermediate representation that captures the "meaning" of the original sentence in order to generate the correct translation, example-based technique is used as well to handle the irregular cases and semantic analysis process is mainly conducted to detect the statements that require the use of SVO construction rather than VSO. Because the research is on E-A MT and many Arabic researchers are interesting is similar researches we use the Arabic characters in the examples; at the same time we 
support these example with their transliteration to help researchers whom can't understand Arabic to get the ideas of the examples.

In the next sections we are going to discuss the morph-syntactic agreement features in the translation into Arabic based on words order combinations VSO and SVO, considering number, gender, case and person features. The structure of these sections are as follows: section 2 presents a literature review, section 3 presents and explained the proposed model, section 4 presents and discusses the results and finally the conclusions are presented.

\section{Review of Literature}

Al-Jarf (2007) said "Although word order has been found to constitute a major difficulty in translation, studies that analyze SVO errors and VSO errors in English-Arabic translation are lacking" [4]. She then attempted to examine the nature of transfer of SVO word order from English. Semantically speaking, the SVO pattern gives emphasis to the subject, whereas the VSO pattern gives emphasis to the verb, the choice between VSO and SVO in Arabic is related to syntactic, pragmatic, discoursal discourse and semantic factors available in a particular context [4] She concluded that the Mastery of SVO and VSO structures in English-Arabic translation can be achieved by improving translation instruction [4].

Kramer (2009) [16] investigated the clausal architecture, and the interaction of syntax with agreement in Arabic, he focused on how the dominant VSO word order and the alternative SVO word order in Middle Egyptian are derived and related. He accounted for an agreement asymmetry between the two word orders: lack of agreement in VSO order and rich agreement in SVO order, he concluded that that VSO order is derived through Verb-to-Tense raising analysis.

$\mathrm{He}$ also claimed that VSO word order is inherently problematic for syntactic theory because standard theories of phrase structure assume that a verb and its complement always form a single constituent, namely, a Verb Phrase (VP) [16].

For many verb-initial languages, the existence of a Verb Phrases (VP) like what is shown in figure (1) has been clearly established in many languages (Arabic [21]; Celtic languages [7] [18][19][25][15]; St'at'imcets Salish [11]; Niuean [27][17]; Chamorro [10], and others).

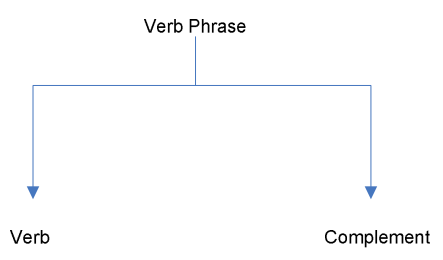

Figure 1. Verb Phrase parsing

In his paper Kramer developed a novel account of agreement as a series of morphological operations that are sensitive to hierarchical structure [16].

Al-Momani (2010) explored the word ordering phenomena in a free word order language like Arabic. He concluded that Arabic is a non-configurational language because it exhibits high word order freedom (i.e. it allows multiple word order permutations). He added, Arabic has the SVO word order as an alternative order and the alternation is conditioned by discourse and semantic features. Thus, the choice between these two orders is triggered by prior information in the discourse. If an entity has not been mentioned before, then the VSO order is preferred; whereas, if an entity has been mentioned before, then the SVO order is necessary [6].

\subsection{Arabic Language Morphology}

Essentially, the Arabic word can be described as follows: 
International Journal of

Soft Computing And Software Engineering (JSCSE)

e-ISSN: 2251-7545

Vol.2,No.8, 2012

Published online: Aug 25, 2012

[prefix1][prefix1] stem [infixes] [suffix1] [suffix2] [12]

The stem (morpheme) is the minimal meaning-bearing unit in a language. Affixes in Arabic can be categorized into three types, the prefixes, suffixes (or postfixes) and infixes [23]. The prefixes are added at beginning of the stem and the suffixes are added at the end of stem, whereas, the infixes are inserted inside the stem. Table 1 below shows some examples of the affixes handling.

Table 1. An Arabic affixes handling examples.

\begin{tabular}{|c|c|c|c|c|c|c|c|}
\hline suffixes2 & suffixes1 & infixes & stem & Prefixes2 & prefixes1 & $\begin{array}{c}\text { Arabic } \\
\text { word }\end{array}$ & Transliteration \\
\hline - & - & - & قتل & - & - & قتل & qtI \\
\hline- & - & - & قتل & - & - & يقتل & yqt। \\
\hline- & - & 1 & قتل & يـ & - & يقاتل & yqatl \\
\hline هم & - & - & قتل & - & - & يقتلهم & yqt/hm \\
\hline هم & - & - & قتل & - & س & سيقتلهم & syqt/hm \\
\hline هم & - & 1 & قتل & - & س & سيقاتلهم & syqatlhm \\
\hline هم & ون & 1 & قتل & 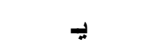 & س & سبقاتلونهم & syqat/wnhm \\
\hline
\end{tabular}

Suffixes in Arabic can be categorized into two basic categories, the suffixes that are attached to the verbs and the suffixes that are added to the nouns [28]. Furthermore, some of the suffixes can be attached to both the noun and verb stem. Nevertheless, Arabic permits the use of up to three suffixes simultaneously to be attached to the end of the same stem [1]. Furthermore, Arabic words are built from roots rather than stems and involve diacritisation. Written Arabic is also characterized by the inconsistent and irregular use of punctuation marks [8]. Table-2 below presents a wide range of suffixes example. 
Table 2. Arabic suffixes examples

\begin{tabular}{|c|c|c|c|c|}
\hline Suffix & Suffix meaning & $\begin{array}{c}\text { Suffix } \\
\text { category }\end{array}$ & Example & phonetics \\
\hline ات & feminine plural & Noun & طالبات & talbat \\
\hline$\ddot{0}$ & Feminine singular & Noun & طالبة & talbh \\
\hline تم & Addresser masculine plural plural & Verb & درستم & drstm \\
\hline تما & Addresser masculine dual plural & Verb & درستما & drstma \\
\hline تن & Addresser feminine plural plural & Verb & مرسنن & drstn \\
\hline تا & Addresser feminine dual plural & Verb & 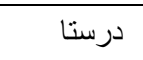 & drsta \\
\hline 9 & Plural masculine & Verb & ينمو & ynmw \\
\hline g & absent masculine plural & Verb & درسوا & drswa \\
\hline ن ي & first person & Verb & 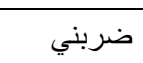 & drbny \\
\hline$ت$ & singular feminine & Verb & 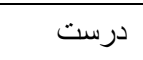 & drst \\
\hline ن & Feminine plural & Both & أكلن & akln \\
\hline 1 & masculine dual & Both & درسا & drsa \\
\hline نا & Masculine plural & Both & 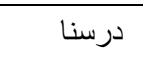 & drsna \\
\hline 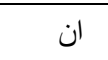 & masculine dual & Both & بدرسان & ydrsan \\
\hline ين & singular feminine & Both & 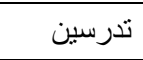 & tdrsyn \\
\hline ون & absent masculine plural & Both & يدرسون & ydrswn \\
\hline 5 & addresser singular & Both & ضربك & drbk \\
\hline ي & singular feminine & Both & د & drsty \\
\hline هـ & absent masculine singular & Both & 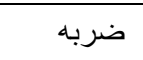 & drbh \\
\hline ها & absent feminine singular & Both & ضربها & drbha \\
\hline 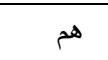 & absent masculine plural & Both & ضربهم & drbhm \\
\hline هن & absent feminine plural & Both & ضربهن & drbhn \\
\hline Los & absent dual & Both & ضربهما & drbhma \\
\hline كم & addresser masculine plural & Both & ضربكم & drbkm \\
\hline كن & addresser feminine plural & Both & ضربكن & drbkn \\
\hline كما & addresser masculine dual & Both & ضربكما & drbkma \\
\hline
\end{tabular}

Arabic language is highly inflectional, rich morphology and relatively free words' order language. It allows the combinations of Subject-Verb-Object (SVO), Verb-Subject-Object (VSO), Verb-ObjectSubject (VOS) and Object-Verb-Subject (OVS) [8]. As for traditional Arab grammarians, VSO is the normal syntactic word order. According to generative grammar, VSO is the basic word order and SVO is derived through subject movement. VSO order is unmarked for focus, emphasis and information 
International Journal of

Soft Computing And Software Engineering (JSCSE)

e-ISSN: 2251-7545

Vol.2,No.8, 2012

Published online: Aug 25, 2012

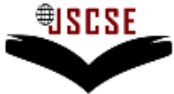

DOI: 10.7321/jscse.v2.n8.5

distribution. The SVO pattern gives emphasis to the subject, whereas the VSO pattern gives emphasis to the verb [3].

\section{Proposed Model}

It is clear from the previous section that VSO and SVO words ordering is important and should be used carefully. This proposal focuses on the agreement requirements based on VSO or SVO pattern is used. The subsequent examples in tables 3 through 6 show different agreement requirements between the verb and the subject depending on whether VSO or SVO words ordering are used. The selection of using VSO or SVO related to the context where we use SVO whenever the subject is our focus.

Table 3. Example 1 (Third person subjects with different genders and numbers)

\begin{tabular}{|c|c|c|c|c|c|}
\hline & & $\mathrm{a}$ & $\mathrm{b}$ & $\mathrm{c}$ & $\mathrm{d}$ \\
\hline \multicolumn{2}{|c|}{ English } & $\begin{array}{l}\text { The girls ate the } \\
\text { vegetables }\end{array}$ & $\begin{array}{l}\text { The girl ate the } \\
\text { vegetables }\end{array}$ & $\begin{array}{l}\text { The boys ate the } \\
\text { vegetables }\end{array}$ & $\begin{array}{l}\text { The boy ate the } \\
\text { vegetables }\end{array}$ \\
\hline \multicolumn{2}{|c|}{ Subject } & girls $(p, f, 3)$ & $\operatorname{girl}(\mathrm{s}, \mathrm{f}, 3)$ & boys $(\mathrm{p}, \mathrm{m}, 3)$ & boy $(\mathrm{s}, \mathrm{m}, 3)$ \\
\hline \multirow{3}{*}{ SVO } & Arabic & البنات اكلن الخضروات & البنت اكلت الخضروات & الخضروات الأوا & الولد اكل الخضروات \\
\hline & Trans. & $\begin{array}{l}\text { albnat akln } \\
\text { alkhdrwat }\end{array}$ & $\begin{array}{l}\text { albnt aklt } \\
\text { alkhdrwat }\end{array}$ & $\begin{array}{l}\text { alawlad aklwa } \\
\text { alkhdrwat }\end{array}$ & $\begin{array}{l}\text { alwld akl } \\
\text { alkhdrwat }\end{array}$ \\
\hline & Agr. & Number, gender, an & erson & & \\
\hline \multirow{3}{*}{ VSO } & Arabic & اكلت البنات الخضروات & اكلت البنت الخضروات & اكل الاو لاد الخضروات & اكل الولد الخضروات \\
\hline & Trans. & $\begin{array}{l}\text { aklt albnat } \\
\text { alkhdrwat }\end{array}$ & $\begin{array}{l}\text { aklt albnt } \\
\text { alkhdrwat }\end{array}$ & $\begin{array}{l}\text { akl alawlad } \\
\text { alkhdrwat }\end{array}$ & $\begin{array}{l}\text { akl alwld } \\
\text { alkhdrwat }\end{array}$ \\
\hline & Agr. & Gender and person & & & \\
\hline
\end{tabular}

Table 4. Example 2 (First person subjects with different numbers)

\begin{tabular}{|c|c|c|c|}
\hline & & $\mathrm{a}$ & $\mathrm{b}$ \\
\hline \multicolumn{2}{|l|}{ English } & We ate the vegetables & I ate the vegetables \\
\hline \multicolumn{2}{|l|}{ Subject } & we $(p,-, 1)$ & $\mathrm{I}(\mathrm{s},-, 1)$ \\
\hline \multirow{3}{*}{ SVO } & Arabic & نحن اكلنا الخضروات & انا اكلت الخضروات \\
\hline & Trans. & nhn aklna alkhdrwat & ana aklt alkhdrwat \\
\hline & Agr. & \multicolumn{2}{|l|}{ Number and person } \\
\hline \multirow{3}{*}{ VSO } & Arabic & اكلنا الخضروات & اكلت الخضروات \\
\hline & Trans. & aklna alkhdrwat & aklt alkhdrwat \\
\hline & Agr. & \multicolumn{2}{|l|}{ Number and person } \\
\hline
\end{tabular}

It is clear from example-1 that verbs have full agreement with their third person subjects, as they are supposed to agree with their subjects in number, gender and person when SVO is used; contrastively when VSO is used, verbs have partial agreement, as they agree with their subjects in gender and person only; while they remain intact with both singular and plural subjects. At the same time, example-2 shows that in both modes (SVO and VSO) the same rules of agreement (number and person) have been applied between verbs and subjects regardless of the gender when the subject is a first person. With more examples, we can show that a lot of agreement variations exist between verb and subject according to the subject features (gender, person, and number), verb tense (past, present, and future), and verb-subject order (SVO and VSO). 
Other features such as humanity and animate also should be considered [3]. Examples 3 and 4 below show how the humanity feature affects the agreement requirements; it is clear from example- 3 that in both modes SVO and VSO the gender and person agreements are maintained with non-human feminine subject, while only the person agreement is maintained with masculine subject; whereas in both genders the singular form of the verb is used; observe that a feminine singular verb is used with masculine plural subject as it is appear in 3.c. The story is differ with human being subject, in SVO words order; number, gender, and person agreements are maintained between the verb and the subject; while in VSO words order; gender and person agreements are maintained, whereas the verb is in singular form regardless of the subject number (singular or plural).

In the same way we can show that different agreement rules are needed with animate/inanimate subjects, with dual (two persons) subject, with more than one subject in the same sentence e.g. "the boy and the girls play football", and also with more than one verb such as "The women eat and speak", and so on.

Table 5. Example 3 (Non-human subjects with different genders and numbers)

\begin{tabular}{|c|c|c|c|c|c|}
\hline & $\mathrm{a}$ & $\mathrm{b}$ & $\mathrm{c}$ & $\bar{d}$ \\
\hline \multicolumn{2}{|c|}{ English } & The cats drink milk & $\begin{array}{l}\text { The cat drinks } \\
\text { milk }\end{array}$ & $\begin{array}{l}\text { The camels eat } \\
\text { grass }\end{array}$ & $\begin{array}{l}\text { The camel eats } \\
\text { grass }\end{array}$ \\
\hline \multicolumn{2}{|c|}{ Subject } & cats $(\mathrm{p}, \mathrm{f}, 3)$ & cat $(\mathrm{s}, \mathrm{f}, 3)$ & camels $(\mathrm{p}, \mathrm{m}, 3)$ & camel $(\mathrm{s}, \mathrm{m}, 3)$ \\
\hline \multirow{3}{*}{ SVO } & Arabic & القطط تشرب الحليب & القطة تشرب الحليب & الجمال تأكل العشب & الجمل يأكل العشب \\
\hline & Trans. & alqtt tshrb alhlyb & alqth tshrb alhlyb & aljmal takl al'eshb & aljml yakl al'eshb \\
\hline & Agr. & \multicolumn{2}{|l|}{ Gender and person } & \multicolumn{2}{|l|}{ Person } \\
\hline \multirow{3}{*}{ VSO } & Arabic & تشرب القطط الحليب & تشرب القطة الحليب & تأكل الجمال العشب & يأكل الجمل العشب \\
\hline & Trans. & tshrb alqtt alhlyb & tshrb alqth alhlyb & takl aljmal al'eshb & yakl aljml al'eshb \\
\hline & Agr. & \multicolumn{2}{|l|}{ Gender and person } & \multicolumn{2}{|l|}{ Person } \\
\hline
\end{tabular}

Table 6. Example 4 (Human subjects with different genders and numbers)

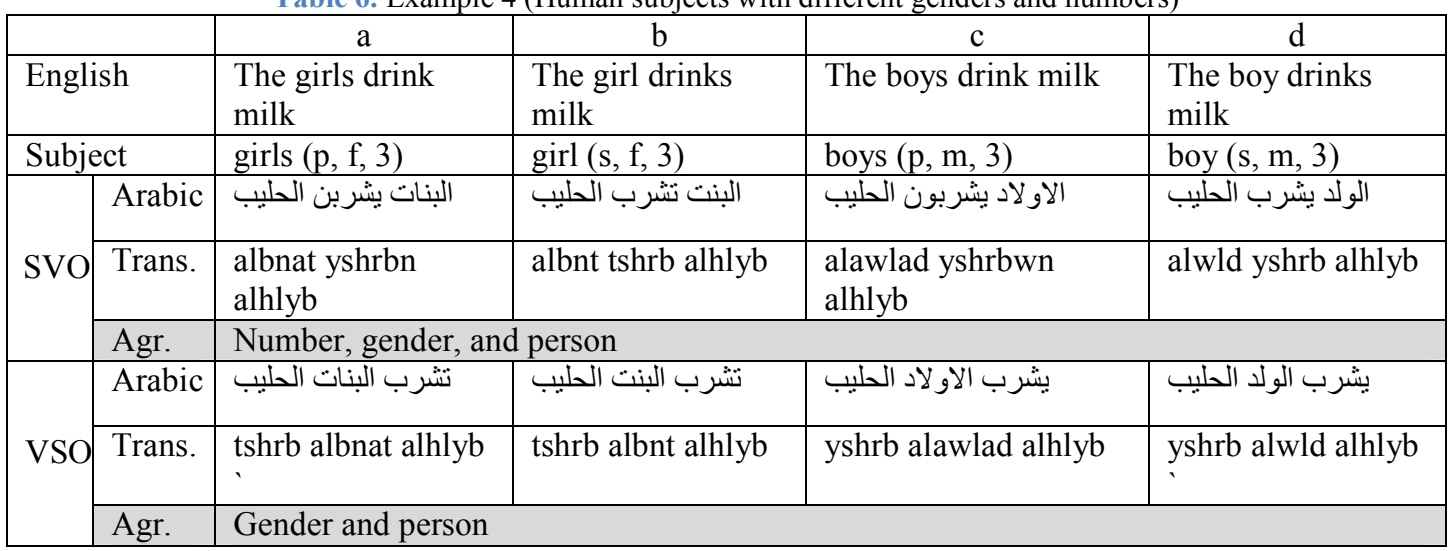

Two important questions emerge, the first one: is it possible to generate all different derivations of the verb for all verbs by following a fixed set of rules? If we neglect the irregular cases, the answer is yes; but we know that nobody can ignore them, therefore we need to build all possible rules and manipulate the irregular cases in a different way such as maintaining an example-based database for them and consult it beside the rules database. The second question is: how the translator will decide 
when to use SVO and when to use VSO since the decision depends on which is our focus: the verb or the subject? It is not easy to answer this question, but in our opinion the translator should use the mostly used mode (VSO) as a default, and modify some sentences to (SVO) according to a semantic analysis of the source text. Figure-1 below illustrates a proposed model to achieve this. The following is an explanation of the model processes with example:

Process 1: Receives the source text (English statement), and pass it to the parser; (The girls ate vegetables).

Process 2: Identifies POS by consulting the English grammar database table; (The/DT girls/NNS ate/VBD the/DT vegetables/NNS).

Process 3: Retrieves Arabic meanings as well as subject features from the English lexicon database table;

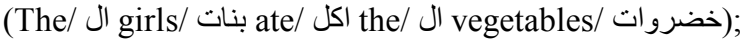

(girls/ plural, feminine, and 3rd person).

Process 4: Analyzes the source text semantically to decide whether SVO should be used or not; (The result will be either yes or no).

Process 5: Creates the correct derivation of the equivalent Arabic verb depending on the results from processes 3 and 4, and the consultation of the Arabic grammar, Arabic lexicon, and E-A examples for irregular verbs' derivations database tables.

(If the result of process 4 is no, then the verb will be اكلت "aklt" since the default mode VSO will be used; if the result is yes, the verb will be اكلن "akln" since SVO mode will be used).

Process 6: Finally, the complete Arabic translation is produces by referencing the words ordering rules database table;

(based on the result of the previous processes, we will get either

aklt albnat alkhdrwat" in the case of using VSO or

"albnat akln alkhdrwat" in the other case SVO). 


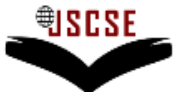

DOI: 10.7321/jscse.v2.n8.5

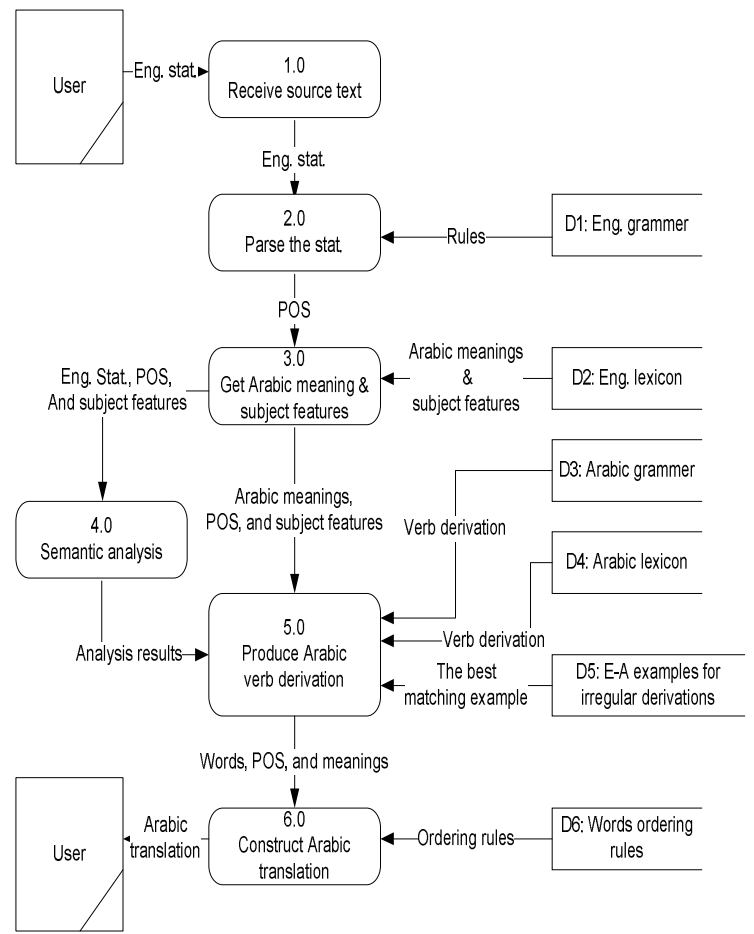

Figure 2. Level 0 DFD of the proposed model

\section{Results and discussion}

We have conducted an experiment to compare our methodology with other MT system in the market, namely; Google, Sakhr, Al Kafi, we then classified the problems that cause that agreement and ordering into

The first one: Agreement problem aspects:

i. Agreement in Definiteness: this problem appeared when the noun has an article and attributive adjective not.

ii. Adjective-Noun Agreement: this problem appeared when the adjectives did not agree in number, gender, case and definiteness with the head nouns.

iii. Verb-Subject Agreement: this problem appeared when the verb did not agree with the subject in person, number, and gender.

iv. Demonstrative-Noun Agreement: this problem appeared when the Arabic demonstrative pronouns are not agreed with their head noun in number, gender, and case.

v. Relative Pronoun-Antecedent Agreement: this problem appeared when the Arabic relative pronouns are not agreed with their controllers in number, gender and case.

vi. Predicate-Subject Agreement: this problem appeared when the Arabic predicate is not agreed with the subject in number and gender.

Second category: Ordering aspects:

vii. Order of the adjective: This problem appeared because the translation of the adjective relative to its described noun is not translated in its right order. In other words, the adjective does not follow the described noun in order

viii. Successive words form an expression: This problem appeared because the successive words that form an expression is translated separately 


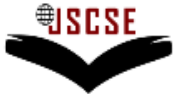

DOI: 10.7321/jscse.v2.n8.5

Third category: both agreement and ordering

ix. Addition and deletion: This problem appeared because the original translation contains extra words that have no corresponding words in the source language, or because the some words in the source language have not translated.

We have evaluated the systems by comparing the translation of each with the original translation and classify the problems that arise based on the error type, and then we assign a suitable score for each problem. the experiments conducted show that the translation by EA-HBMT score an average of 96.1 percent as shown in Table 7.

Table 7. Experiment I results

\begin{tabular}{|llllc|}
\hline MT & ALKAFI & GOOGLE & TARJIM & EA-HBMT \\
\hline Percentage & $92.1 \%$ & $84.6 \%$ & 94.2 & $96.1 \%$ \\
\hline
\end{tabular}

\section{Future work and limitation.}

Other types of verbs need to be handled in the future, for example, weak verbs as well as doubled verbs, Weak verbs are those verbs which do not contain one of the alif (hamza), waaw or yaa as one of the root letters, whereas doubled verbs are arisen when any triliteral rooted verb's second and third of the three root letters is the same letter. When the third letter contains a vowel, then second and third letters are combined and written with a \$adda شدَّ

However, extra light will be shed on other grammatical states, i.e., personal pronouns, relative pronouns, demonstrative pronouns, verbal nouns and numbers.

This paper has dealt with Modern Standard Arabic (MSA) that derived from classical Arabic.

\section{Conclusion}

This research has dealt with two features that greatly affect the output quality of machine translation; they are word ordering and agreement.

In this paper we have investigated the morph-syntactic agreement features in the translation into Arabic based on words order combinations VSO and SVO. The recent study attempted to examine the nature of using VSO and SVO word order. This paper investigates different rules to manage the problem of morphological and syntactic ambiguities in Arabic that arisen due to the richness and complexity of Arabic morphology.

Arabic as a Target Language (TL) in this paper is highly inflectional, rich morphology and relatively free word's order language; it allows the combinations of SVO, VSO, VOS and OVS.

The two experiments have proven that EA-HBMT comes first, then ALKafi followed by Tarjim and the lowest score was Google.

Through the investigation of the available MTs and related researches, as well as the flexibility of Arabic language grammars, we concluded that we are far a way from getting an English-Arabic MT up to the accuracy of human translation due to either faulty analysis of the SL text or faulty generation of the TL text. At the same time we can enhance the output quality by feeding the system with adequate, robust and completed rules to deal with the morph-syntactic agreement features.

In this research, we proposed an approach that is supposed to enhance the MT quality by selecting the correct words' order through a semantic analysis, and direct the translator to use an example-based technique to handle the irregular cases that are difficult to be generated by the available rules.

\section{References}

[1] Abu-Ata B., "An Arabic stemming algorithm on ERA for information retrieval", PhD. Thesis, Universiti Kebangsaan Malaysia, 2001. 
[2] Abu Shqeer O., "Handling Agreement and Word Reordering in English to Arabic Machine Translation", Master Thesis submitted to University of Sains Malaysia, 2002.

[3] Abu Shquier M. and Sembok T., "Word Agreement and ordering In English-Arabic machine translation", Proceeding of the International Symposium on Information Technology, 2008.

[4] Al-Jarf R., "SVO Word Order Errors in English-Arabic Translation", Translators' Journal, vol. 52, 2007, p. 299-308, 2007.

[5] Al-Khuli, M., (1982): Al-Taraakeeb al-ahaa?i9a fi llugha al-Arabiyya (Common Structures in Arabic), Dar Al-Uloom Publishing Co.

[6] Al-Momani, I. 2010. DOES THE VP NODE EXIST IN MODERN STANDARD ARABIC? Journal of Language and Literature, ISSN: 2078-0303, May, 2010.

[7] Anderson, Stephen and Sandra Chung. 1977. On grammatical relations and clause structure in verb initial languages. In Grammatical Relations: Syntax and Semantics 8, eds. Peter Cole and Jerrold Sadock. 1-25. New York: Academic Press.

[8] Attia M., "Handling Arabic Morphological and Syntactic Ambiguity within the LFG Framework with a View to Machine Translation", PhD Thesis, University of Manchester. Faculty of Humanities, 2008

[9] Corbett G. "Agreement: Terms and boundaries. In William Griffin", The Role of Agreement in Natural Language, Proceedings of Texas Linguistic Society Conference, Austin, Texas, 2001.

[10] Chung, S., 1983. The ECP and government in Chamorro. Natural Language andLinguistic Theory 1: 209-244.

[11] Davis, Henry. 2005. Coordination and constituency in St'at'imcets (Lillooet Salish).

In Verb First: On the Syntax of Verb-Initial Languages, eds. Andrew Carnie, Heidi Harley and Sheila Ann Dooley. 31-64. Amsterdam: John Benjamins. Depuydt, Leo. 1993. Conjunction, Contiguity, Contingency. On Relationships

[12] El-Sadany T., and Hashish M., "An Arabic morphological system". IBM Systems Journal 28 (4): 600-612., 1989.

[13] Feras Saeed. 2010 Word Order and Agreement Asymmetry (English and Foreign Languages University, Hyderabad). The 5th annual Moscow Student conference on Linguistics

[14] Hatem A. and Omer N., "Syntactic Reordering for Arabic- English Phrase-Based Machine Translation", 2010.

[15] Hendrick, R., 2000. Celtic initials. In The Syntax of Verb-Initial Languages, eds. Andrew Carnie and Eithne Guilfoyle. 13-38. Oxford: Oxford University Press.

[16] Kramer, R. (2009), VSO and SVO word order in Middle Egyptian. In Afroasiatic Studies in Memory of Robert Hetzron, ed. C. Häberl. Cambridge: Cambridge Scholars Press. 92-147.

[17] Massam, D., 2000. VSO and VOS: aspects of Niuean word order. In The Syntax of Verb-Initial Languages, eds. Andrew Carnie and Eithne Guilfoyle. 143-162. Oxford: Oxford University Press.

[18] McCloskey, James. 1983. A VP in a VSO language. In Order, Concord and Constituency, eds. Gerald Gazdar, Geoff Pullum and Ivan Sag. 9-56. Dordrecht: Foris.

[19] McCloskey, James. 1991. Clause structure, ellipsis and proper government in Irish. Lingua 85: 259-302.

[20] Mohammad, M.A., 2000. Word Order, Agreement and Pronominalization in Standard and Palestinian Arabic. Amsterdam: John Benjamins.

[21] Ryding K., "A Reference Grammar of Modern Standard Arabic. Cambridge": Cambridge University Press, 2005

[22] Saliba B., and Al-Dannan A., "Automatic morphological analysis of Arabic: a study of content word analysis", Proc. of the First Kuwait Computer conference. pp. 231-243., 1990.

[23] Sharif, M. (1993): Al-Tarakeeb al-naHwiyya (Grammatical Structures), Al-Shabaab Bookstore Publishing.

[24] Sproat, Richard. 1985. Welsh syntax and VSO structure. Natural Language and Linguistic Theory 3: 173-216. 
International Journal of

Soft Computing And Software Engineering (JSCSE)

e-ISSN: 2251-7545

Vol.2,No.8, 2012

Published online: Aug 25, 2012

DOI: 10.7321/jscse.v2.n8.5

[25] Wickens G., "Arabic Grammar", Cambridge: Cambridge University Press, 1980.

[26] Woolford, Ellen. 1991. VP-Internal Subjects in VSO and nonconfigurational languages. Linguistic Inquiry 22: 503-540.

[27] Yusif J., "Automatic Part Of Speech Tagger for Arabic Language using Neural Network". PhD Thesis submitted to National University of Malaysia, 2007.

[28] http://mylanguages.org/arabic_romanization.php visited February, 2012

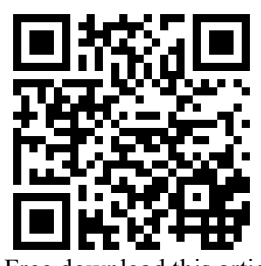

Free download this article and more information 